\title{
Entre la lectura procesual y la escucha de diversidad de seres ocupacionales...
}

Reseña del libro: Ocupación: sentido, realización y libertad. Diálogos ocupacionales en torno al sujeto, la sociedad y el medio ambiente. Rojas Castillo, Claudia Patricia (Ed.)².

Dora Inés Munevar M. ${ }^{3}$

Munevar, D.I. (2013). Entre la lectura procesual y la escucha de diversidad de seres ocupacionales... Revista Ocupación Humana, 13 (1), pp. 64-70.

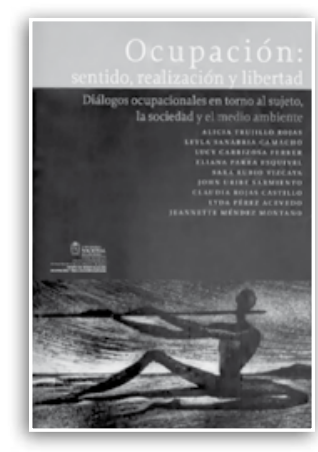

Si el lenguaje tiene un significado, entonces lo que hay que estudiar es el lenguaje, el modo en que el lenguaje se refiere al mundo. En cambio, si el modo en que los sujetos interpretamos es el lugar donde ponemos el acento de la comunicación, lo que tenemos que hacer, más que una filosofía del lenguaje, es una filosofía de la escucha.

Diana Maffia, 2008.

Mientras escucho las múltiples voces de mujeres y de hombres que permanecen en el primer piso del edificio 471, escucho el recrear sonoro del viento agitando las copas de los árboles que diviso por la ventana de la oficina 514. Con este doble telón académico de fondo, comienzo la lectura reflexiva de la versión digital de cinco capítulos estrechamente relacionados entre sí pues constituyen un conjunto de posibilidades significativas acerca de las ocupaciones en acción, lo mismo que de los seres ocupacionales en concreto.

Me detengo en la arquitectura del libro del que forman parte dichos capítulos para entrever la presencia individual, escuchar las voces compartidas y leer entre líneas el trabajo colectivo de quienes han escrito sus páginas; pronto advierto que se trata de perso-

\footnotetext{
${ }^{1}$ Ciudad Universitaria, escrito y compartido en septiembre de 2011, repensado y anotado en mayo de 2013.

2 Universidad Nacional de Colombia, sede Bogotá. Facultad de Medicina. Grupo de Investigación Ocupación y Realización Humana. Alicia Trujillo Rojas, Leyla H. Sanabria Camacho, Lucy Carrizosa Ferrer, Eliana Isabel Parra Esquivel, Sara Ximena Rubio Vizcaya, John Jairo Uribe Sarmiento, Claudia Patricia Rojas Castillo, Lyda Otilia Pérez Acevedo, Jeannette Amanda Méndez Montaño. ISBN: 978-958-719-729-7. Imagen de portada: Flautista negro, Luis Ángel Rengifo, 1968.

${ }^{3}$ Abogada, fonoaudióloga. Magistra en Sociología de la Educación. Doctora en Teoría Sociológica: Comunicación, Conocimiento y Cultura. Posdoctora en Estudios de Género. Profesora titular, Universidad Nacional de Colombia; adscrita al Departamento de Comunicación Humana, vinculada a la Escuela de Estudios de Género e investigadora del Instituto de Desarrollo Humano (Dis)Capacidades, Diversidades - I.D.H. dimunevarm@ unal.edu.co
} 
nas interesadas en la ocupación como saber pero también de personas que han estado propiciando acercamientos orientados por los seres ocupacionales puesto que "la ocupación está mediada por un sentido del ser y el hacer con otros" (p. 86).

Al escudriñar con curiosidad los temas que constituyen el libro encuentro nombres, campos de formación, intereses investigativos y trayectorias académicas individualizadas, es decir, reconozco que en la autoría individual o grupal subyacen diversas ocupaciones; también percibo distintos diálogos inter-generacionales en torno a la ocupación humana como objeto de estudio de una carrera cuyos orígenes institucionales y generizados en el país nos remontan a la década de los años sesenta del siglo pasado: terapia ocupacional, una de las carreras abiertas en la Universidad Nacional como respuesta a las demandas históricas de las mujeres para acceder a la educación superior colombiana. Y, agudizando el oído para conjugar los contenidos, identifico el sentido de algunas interpelaciones en torno a la ocupación humana como área de conocimiento que busca insistentemente un lugar propio en el mundo de los saberes científicos, lugar que varía en términos geopolíticos porque, por ejemplo:

"en la Universidad del Sur de California, donde se originó la ciencia ocupacional, reconocen que su mirada ha privilegiado el análisis del individuo, dada la orientación ideológica de esa sociedad, mientras que países como Australia, Canadá, Inglaterra, Suecia y Sudáfrica optan por incorporar la reflexión de las complejidades socioculturales" (p. 37).

\section{Ocupación: sentido, realización y} libertad, es el título de este libro colectivo elaborado por integrantes del grupo de investigación denominado Ocupación y Realización Humana de la Universidad Nacional de Colombia. Desde un comienzo es posible leer en sus 160 páginas, ideas afines, en términos arendtianos, a un empezar algo nuevo o al hecho de aparecer o emerger para comunicar la convicción de que la ocupación constituye una noción compleja; pero también a distintos actos de movilización intelectual para repensar los compromisos de la universidad pública "desde una perspectiva emancipadora en un continente que ha experimentado regímenes históricos de opresión“ (p. 89).

Diálogos ocupacionales en torno al sujeto, la sociedad y el medio ambiente, es el subtítulo de este mismo libro que contiene una propuesta procesual centrada en la incorporación del sentido y en la emergencia de las subjetividades, esto es, en reconocer la pluralidad humana para incrementar los encuentros, propiciar los re-encuentros y activar las interacciones ocupacionales más allá de las experticias profesionales, de las fronteras disciplinares o de los dominios geopolíticos "reafirmando que desde la región latinoamericana es necesario asumir una perspectiva de diversidad, la cual se hace presente en los cuerpos y en las formas de hacer y de ocuparse" (p. 89). Y, pese a que no aparece de manera explícita, se pueden trazar líneas de fuga para dar paso a los cuerpos habitados por subjetividades sexuadas, generizadas, carenciadas por la discapacidad, racializadas o etnizadas. 
Ocho autoras y un autor comparten sus apuestas académicas mediadas por la reflexividad escrita. Quienes consulten el libro con intención de leerlo pueden hacerlo en cualquier orden dado que cada capítulo rehace aspectos conceptuales de los estudios en terapia ocupacional y contextualiza sus avances en el ámbito de una ciencia ocupacional en permanente re-elaboración; sus lectoras y sus lectores van a revivir las discusiones subyacentes en la comprensión de la ocupación, con sus acepciones procesuales centradas en los componentes subjetivantes, socioculturales y ecológicos, lo mismo que en la configuración del modelo conceptual o marco orientador del estudio formal de la ocupación, sobre todo reconociendo de modo manifiesto que "el lenguaje de la ciencia ocupacional construye una conceptualización de la realidad que es, a su vez, una relación de poder" (p. 105).

Quizás por eso mismo, en ese transitar colectivo por el mundo de los saberes formalizados, las autoras y el autor del libro han terminado haciendo preguntas relacionadas con unos seres ocupacionales que reclaman su reconocimiento como seres diferenciados y con diversidad de ocupaciones entendidas como construcciones sociales. Son preguntas que pretenden analizar las relaciones de fuerza y de sentido vinculadas a las experiencias ocupacionales; son preguntas que se vuelven sobre la clase de conocimientos que procuran producir; y son preguntas que demandan la acción de quienes leen pues se les convoca a optar por la posibilidad de mantener las hegemonías o por la posibilidad de desplegar su voluntad para deconstruirlas.
Los contenidos de los distintos capítulos no solamente articulan los hallazgos de dos investigaciones previas (Transformaciones conceptuales y pedagógicas en el campo de la ocupación humana, 2008; y Modelo conceptual para orientar el estudio en ciencia de la ocupación humana, 2010), sino que incorporan la comprensión de la ocupación humana, la ocupación como proceso subjetivante, la ocupación como proceso sociocultural, la ocupación como proceso ecológico y el modelo conceptual para orientar el estudio en ciencia de la ocupación humana. Estos caminos trazados por las autoras y por el autor plantean el lugar ocupado por el conocimiento para entender la ocupación humana y transformar la vida de mujeres, hombres, niñas, niños, jóvenes y mayores, porque comparten una premisa de partida: la ocupación abre posibilidades de realización personal, ejercicio de libertad y construcción de sentido.

Las transformaciones de los individuos con [y en] las ocupaciones revelan movimientos y activan movilizaciones necesarias para reconocer los fundamentos conceptuales, las argumentaciones descriptivas, las rutas interpretativas y los cuestionamientos a los modos de pensar los saberes ocupacionales; por consiguiente, están contribuyendo a ampliar las posibilidades epistémicas para develar las "formas de dominación en las que no se requiere el uso de la fuerza" (p. 105), y para ubicar históricamente las relaciones de sentido hegemónicas que legitiman y controlan la producción, la circulación y la recepción de las significaciones sociales. En este contexto, los sentidos sirven para replantear las preguntas hechas al núcleo académico 
de los saberes ocupacionales tal como lo revela la creciente bibliografía relacionada que circula a nivel nacional e internacional:

"la filosofía, las ciencias sociales, las ciencias biológicas, la ciencia ocupacional y la terapia ocupacional sugieren puntos clave de diálogo y reflexión ( ). Sus posturas deben ser materia de análisis permanente por ser éste el terreno donde se debaten las cuestiones más fundamentales referentes a los orígenes y fines de la vida, la naturaleza, el ser y la existencia y sobre el conocimiento, sus fuentes y sus explicaciones, entre otros. Por otra parte, conviene reconocer en cuáles escuelas del pensamiento universal tienen asidero las ideas y convicciones que se defienden, por ejemplo, para explicar la selección y desempeño de ocupaciones cotidianas o el proceso del pensar académico y en el quehacer investigativo" (pp. 26-27).

Por eso mismo, continúo la lectura considerando algunos argumentos cercanos "a la interdependencia con la dinámica sociopolítica y económica, las manifestaciones culturales y el ecosistema" (p. 37), pero también a "las situaciones ocupacionales en Latinoamérica y Colombia" (p. 198), a la justicia ocupacional entendida en función de los "sistemas socioculturales y económicos ( ), una lucha por significar las ocupaciones como expresiones de capacidades conectadas por el bienestar comunitario" (pp. 120, 122), y, por supuesto, a la configuración de "comunidades ecosostenibles, centradas en la ocupación" (p. 140). Así, me dejo guiar por los modos como se van articulando los movimientos registrados en el texto para explicar los procesos configuradores de la ocupación, aproximarse a las construcciones teóricas e interrogar la composición, las actividades, las acciones o los haceres de las comunidades. Igualmente, en las vivencias, en las experiencias y en las estructuras es posible reconocer tanto las diferencias materiales y simbólicas como las oportunidades vitales o las recomposiciones identitarias vividas por la gente, cuestiones que demandan otros análisis particulares "que consulten la historia y realidad colombiana y latinoamericana, tema que hasta ahora no ha sido materia de estudio sistemático" (p. 46).

Retomo esta ruta analítica para reconstruir los debates contemporáneos acerca de la legitimación de saberes, al vaivén de las dinámicas sociales, académicas y políticas, pensando que su problematización puede constituirse en "un punto de partida para la construcción de la ciencia ocupacional en Colombia" (p. 46). Y, retomando lo dicho en el mismo texto, esta discrepancia establece, recorre y da cuenta de las interacciones entre ser, hacer y llegar a ser, lo mismo que entre la diversidad de seres ocupacionales, el lugar que ocupan individualmente en sociedades inequitativas y la multiplicidad de relatos ocupacionales a compartir.

Mientras emprendo la relectura de los capítulos como si de una espiral se tratase, van surgiendo, además de puntualizaciones sobre "la implementación del capitalismo en Colombia como un proceso de 'sujeción', de vinculación de los sujetos a una sociedad de trabajo bajo ideales de 'progreso', de vinculación a las reglas de juego y los estilos de vida capitalistas" (p. 112), los procesos de transformación entretejidos con ocho proposiciones expuestas a lo largo de las páginas 46 a 
63. Por eso, me gustaría destacar aquí que el cimiento de:

"la ocupación como proceso sociocultural se expresa en la dinámica propia de las relaciones de fuerza (expresadas en las jerarquías, diferencias, desigualdades, trasgresiones, resistencias y subversiones de la experiencia ocupacional) y de las relaciones de sentido (modo como se define el porqué y el para qué de las acciones cotidianas)".

Conjugo dicho cimiento con el hecho de que "la ocupación promueve la organización del tiempo y el espa$\mathrm{Cio}^{\prime \prime}$, sin dejar de observar que, a la vez, la ocupación "es influenciada por propiedades y condiciones ambientales y contextuales" que rodean a mujeres, hombres, niñas, niños, jóvenes y mayores, de todas las edades y condiciones, y sabiendo que:

"los factores históricos son relevantes para comprender la relación entre el sistema humano y el ambiental, en tanto las personas, los ambientes y sus interacciones tienen una historia propia, que no puede ser analizada separadamente" (p. 133).

No es posible olvidar que la ocupación, como una constante presente en la realidad histórica de los seres humanos, instituye un asunto clave para resituar su lugar en la organización académica de saberes. Este reconocimiento implica que "tanto los significados como los sentidos se constituyen en escenarios complejos cruzados por relaciones de fuerza: [y] ambos casos se configuran como vehículos de hegemonías sociales y luchas ideológicas" (p. 104).
Los estudios ocupacionales en el extranjero han sido liderados por más mujeres que hombres, ya sea trabajando en grupo o de manera individual; sus aportes ofrecen explicaciones en torno a los modos de reconocer sus rasgos y sus alcances en la vida cotidiana, en el mundo académico y en el trabajo investigativo. Con los avances provenientes de terapeutas ocupacionales y de cientistas ocupacionales de países anglosajones, quienes hacen esta clase de estudios interrogan sus propios compromisos en relación con "la subjetivación de la persona, incluido su sustrato corporal, el devenir sociocultural y el intercambio ecológico" (p. 46). Las contribuciones colombianas presentadas en el libro, derivadas de los procesos investigativos ya mencionados, permiten adentrarse en las lecturas de los procesos subjetivantes, socioculturales y ecológicos de una manera relacional para afinar la escucha de otras voces (las de los seres ocupacionales) y para apreciar los giros interpretativos (anclados en factores socioculturales y ecológicos).

En ambos casos, abordar la vida cotidiana de mujeres y hombres, de niñas y niños, de jóvenes y mayores, además de convocar la presencia individual diferenciada, exige repensar el reconocimiento de las interseccionalidades arraigadas en identidades, discriminaciones y resistencias por razones de género, clase, etnicidad, capacidad, sexualidad, condiciones de salud, edad o generación. Reconocer sin más tardanza conceptual esta vía es urgente porque las experiencias singulares vividas permiten cuestionar desde la academia temas, principios y teorías adscritas a la corriente princi- 
pal o hegemónica; una alternativa posible porque:

“a través de la ocupación como acción-realización impermanente, el sujeto está dinamizando constantemente su base evolutiva, la cual trasciende la esfera de lo biológico e implica considerar que para el ser humano, la evolución tiene lugar junto a procesos culturales activados por el lenguaje y la interacción de fuerzas (poderes) que también evolucionan. La ocupación así expuesta aparece como una expresión de lo humano, donde cabe preguntarse qué momentos del proceso de constitución de ese sujeto humano pasan por la colectividad y cuáles son un proceso de base individual" (p. 73).

Si bien dichos cuestionamientos pueden interpelar los modos en que se han configurado los saberes ocupacionales, no todos los caminos trazados conducen estrictamente a los mismos debates sobre las ocupaciones humanas, como tampoco a los mismos lugares de enunciación. No obstante estas restricciones, todos los capítulos ofrecen particularidades y adoptan expresiones de trabajo colectivo -excepto un capitulo que es de autoría individual-, estructuran ejes comunes y configuran relaciones comprensivas pues reconstruyen los saberes ocupacionales siguiendo las huellas de "lo posible, y con lo realizable a partir de la experiencia corporal" (p. 88); una experiencia que, cuando se analiza en términos de poder, contiene y expresa jerarquías, diferencias y desigualdades pero que también abriga y da cabida a trasgresiones, resistencias y subversiones desde los mismos cimientos ocupacionales.

Las elaboraciones epistémicas emergentes plantean otros horizontes interpretativos para movilizar transfor- maciones entre quienes hacen y piensan las ocupaciones dentro y fuera de la academia. Aquí se develan los vínculos de las ocupaciones tejidos a partir de "una forma del lenguajear humano, esto es, asociado a los diversos dominios de acción" (p. 111), sobre todo al dominio relacionado con el agenciamiento y con la configuración del cambio para subvertir los fundamentos del proceso de producción de ese sentido hegemónico que genera sujeciones; por tanto, urge incorporar la dimensión política de la ocupación, con giros anclados en la creatividad como eje de nuevos acuerdos interculturales para que, más prontamente, "constituyan pactos sociales sensibles, justos y contextuados a la realidad colombiana y regional" (p. 123).

De este modo, se procura repensar el alcance de las interacciones, intersecciones e incorporaciones deseables entre persona-sujeto, sociedad, cultura y ecología para ir más allá de las fronteras de los modelos conceptuales y de los modos de ilustrarlos o graficarlos $y$, en consecuencia, acompañar más los flujos que los límites, los interrogantes que las certezas (p. 149); y para propiciar la escucha de las subjetividades y sus narraciones más que la lectura de los contenidos establecidos o de las definiciones fijadas. En fin, se trata de centrarse mucho más en la presencia de la diversidad de mujeres, hombres, niñas, niños, jóvenes y mayores habitantes de estos territorios colombianos que en las representaciones o abstracciones que eliden su agencia con lenguajes que conservan sesgos sexistas.

En este último sentido, tras la escucha de la diversidad de seres ocupacionales, les invito a lenguajear el texto con el propósito de recrear nuevas po 
sibilidades para nombrarles e incluirles mediante la palabra hablada, escrita, señada, imaginada, representada, escuchada o leída. Para ello, las lectoras y los lectores van a releer sus páginas desde los lugares de enunciación concretos ocupados por cuatro mujeres que comparten reflexiones en torno a la comprensión de la ocupación, una de ellas se convierte en coautora junto a otra mujer para abordar los procesos subjetivantes; por un hombre y dos mujeres que han estado reconstruyendo diferentes relaciones de fuerza, incluidas las relaciones de sentido con la intencionalidad expresa de demandar la acción de una justicia ocupacional; por una mujer que relata los aportes de los ecofeminismos al momento de precisar las expresiones ecológicas de la ocupación; y por un grupo de investigación integrado por nueve investigadoras activas, con el acompañamiento de doce alumnas y de dos alumnos y el liderazgo de una profesora $^{4}$ de la Universidad Nacional de Colombia 5 .

\section{Referencias}

Maffia, D. (s.f.) Contra las dicotomías: Feminismo y epistemología crítica. Seminario de Epistemología Feminista. Facultad de Filosofía y Letras, Universidad de Buenos Aires. Recuperado en septiembre de 2011 de: http://dianamaffia.com. ar/?page $\mathrm{id}=11$.

Munévar, D.I. (2011). Mujeres cultivando saberes académicos. En: Munévar, D.I., (Ed.). Saberes de mujeres: reconocidos y menos reconocidos (p. 15-36). Bogotá: Editorial Universidad Nacional de Colombia.

\footnotetext{
${ }^{4}$ Integra la quinta parte de los grupos liderados por mujeres que se concentran en ciencias de la salud. En su categoría (D), las lideresas han obtenido una gama diversa de títulos que van de especialización a posdoctorado. ${ }^{5}$ http://201.234.78.173:8080/gruplac/jsp/visualiza/visualizagr.jsp?nro=00000000003970
} 


\section{Guía abreviada para autores}

Antes de enviar un artículo a la Revista Ocupación Humana, los autores deben asegurarse de haber leído la "Guía de Autores" completa, disponible en la página http://www.tocolombia.org/revistaoh/. Los artículos o documentos deben enviarse al correo electrónico editorial@tocolombia.org, adjuntando la carta remisoria con los nombres y firmas del autor o autores, especificando sus correspondientes datos de identificación (nombre, dirección, dirección electrónica y teléfonos). Se anexará además una carta con la certificación de responsabilidad del (los) autor(es), la cesión de los derechos de publicación y la declaración de conflictos de interés. Una vez recibido el artículo y tras la verificación del cumplimiento de los requisitos, la Editora hace su presentación ante los Comités Editorial y Científico, quienes evalúan su mérito científico. Posteriormente el artículo será sometido a evaluación por pares, quienes revisarán y aprobarán su contenido y podrán realizar observaciones sobre el mismo.

La Revista considera la publicación de documentos de los siguientes tipos: Artículos de Investigación, de reflexión, de revisión, reportes de caso, revisiones de tema, cartas al editor, reseñas bibliográficas, artículos cortos y revisiones temáticas.

Los textos presentados reunirán las siguientes características: Elaboración en tamaño carta, letra Arial, tamaño 12, interlineado 1.15, y referencias bibliográficas en letra tamaño 10. La extensión máxima será de 15 páginas, las cuales deben ir numeradas. Debe incluirse un resumen en español e inglés, entre 150 y 200 palabras, con sus respectivas palabras clave (máximo cinco) de acuerdo al índice de Tesauro de la Unesco, los Descriptores en Ciencias de la Salud DeCS y $\mathrm{MeSH}$. Es responsabilidad de los autores asegurar la calidad de la traducción presentada.

Las tablas y figuras deben estar referenciados en el texto y contener numeración y título, si ya han sido publicadas, se debe mencionar la fuente. Si el artículo cuenta con fotografías, estas deben ser de alta resolución y calidad; si se trata de imágenes de usuarios o pacientes, se debe anexar el respectivo consentimiento para su publicación.

Las figuras y tablas serán enviados en archivos separados del texto, en formato Word para Windows; deben ser legibles, presentados en blanco y negro o en escala de grises. Se deben seguir las normas de la American Psychological Association (APA), en su última versión publicada.

Las referencias bibliográficas se organizarán en orden alfabético según el primer apellido del autor y se ubicarán en una hoja aparte al final del artículo, con la estructura que se presenta a continuación:

Trujillo, A. (2002). Terapia ocupacional: conocimiento y práctica en Colombia. Bogotá: Editorial Universidad Nacional de Colombia.

Otro tipo de citación (revistas, artículos electrónicos, entre otros) será consultada por los autores en la norma APA.

\section{Suscripción a la Revista}

Los profesionales y estudiantes colegiados reciben en su dirección de correspondencia en Colombia y sin costo alguno, los dos números anuales de la Revista.

Para los interesados no colegiados los costos son:

- Valor unitario: $\$ 20.000$

- Suscripción anual para residentes en Colombia (dos números + gastos de envío a nivel nacional): $\$ 50.000$.

- Suscripción anual para residentes fuera del país: $\$ 50.000$ + gastos de envío (tarifa vigente al momento del envío).

Para suscribirse a la Revista Ocupación Humana diligencie el formato y envíelo por correo postal a la Cra. 9B \# 117 A 15, Bogotá - Colombia, o escaneado al correo electrónico editorial@tocolombia.org

Formato de suscripción:

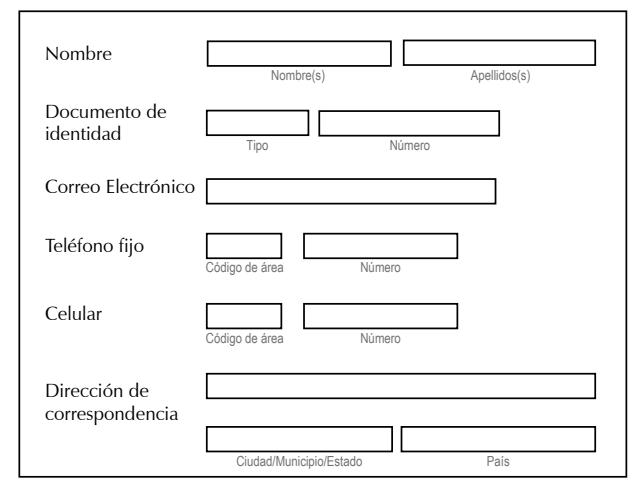

